\title{
Research on the Complexity of Information System Development
}

\author{
Wei Chen ${ }^{1}$ and Yan Zhang ${ }^{2}$ \\ JiangXi Technical College of Manufacturing , Department of Information Engineering, JiangXi \\ Nanchang, 330095 \\ Jiangxi Technical College of Manufacturing, Department of Information Engineering, JiangXi \\ Nanchang, 330095
}

Keywords: Information technology; Information system; Electronic data

\begin{abstract}
Revolution of information technology extends human's brain, develops human's ability of acquiring and storing knowledge, accelerates human's application of scientific technology and improves the efficiency of economic development in human's society. Information technology industry has become a major mark of advanced productivity as well as the accelerator of knowledge economy. This paper summarizes three opinions on developing information system by analyzing the formation and development process of information system with summary of main factors during developing information system. Besides, it proposes the structural model of information system development system so that it explores the reasons, essential features and the major problems which are needed to be solved during information system development from the perspective of complicated science.
\end{abstract}

\section{Introduction}

During the development of human society, technology has brought extremely deep influence on social progress. In 1769, Watt invented the first steam machine, which stimulated the mechanical progress. Years ago, Thomas Edison invented electricity, which accelerated the progress of electrification. Nowadays, with the development and popularization of information technology, human's society enters into informatization age rapidly. Humans are now having highly efficient, professional and diversified development and employment of information resources combined with modern computer technology and communication technology. Revolution of information technology extends human's brain, develops human's ability of acquiring and storing knowledge, accelerates human's application of scientific technology and improves the efficiency of economic development in human's society. Information has become a major element of productivity as well as strategic resource of social development. Information technology industry has become a major mark of advanced productivity as well as the accelerator of knowledge economy.

\section{Methods}

As information system is a kind of professional system, different kinds of methods can be used to define it. The widely accepted definition is as follows. The so-called information system is the collection of related elements or components which can be used to collect input, operation and 
storage processing data and information with the supply of feedback mechanism so as to realize its goals.

During the development of information system, multiple-level structural model has been proposed for different objects, scopes, targets and points according to different demand levels. To sum up, there are three typical methods of classifying hierarchical structure.

Hierarchical structure model of information system based on management process. R.V.Head has proposed the hierarchical structure model of information system based on the three-level management model by dividing management process into three-level strategic plans, management control and operational control.

The model is made up by four levels. The lowest level is primary information system, which is used to deal with general issues. The second level is information system used for operational planning, decision making and control. The third level is information system based on assistant tactical plans and decision activities. The fourth level is information system which supports strategic decisions made by the highest decision makers.

Hierarchical structure model of information system based on computer technology. In 1946, the first computer in the world was researched in Pennsylvania, America; and by far, computer technology has experienced three major leaps from Microcomputer Local Network to Wide Area Network. With the leaps of computer technology, information system has experienced deep changes on its connotation and development technology. Hierarchical structure model of information system based on computer technology has divided information system into three levels.

Hierarchical structure model of information system based on organizational units. Hierarchical structure model of information system based on the classification of organizational units divides information system into individuals, departments, organizations and environment and so on according to different organizational groups that it serves. Information system on different levels is submitted to organizational rules of different organizational units and serve for benefits of different organizational units.

Hierarchical structure of information system should be the combination of the three structures above on the whole. Development and variations of information system on the three dimensions reflect development process of information system.

The development of information system is remarkable, and its future development trend can be predicted according to its development rules in the past 50 years, especially its rapid development in application field.

1) Intellectualization

2) Integration and extension

3) Information sharing

It has long been a controversial problem for researching the development of information system during the overall information system development and software engineering field. Actually, it is a problem regarding knowing about object as well as developing a practical system. Due to limitation of technology, research on this problem had not been studied specifically. However, in recent years, with the rapid development of software tool and technology, technological environment of researching this problem has been changed greatly. The traditional system realization methods such as programming, debugging and document filing and so on have been replaced by new software development tools gradually. Meanwhile, some sections during traditional analysis and design process have also been gradually replaced by computer subsidiary development tools such as graphs, 
drawings and document filing and so on, which have not been hot topics for people's research and argument. Therefore, the focus of research on the development method of overall system has been inclined to preliminary work. That is, cognitive view on the development of information system has become the key problem in this field.

At present, there are mainly three cognitive views on the development of information system by analyzing various kinds of documents and cases.

1. View on technology

2. View on society

3. View on the integration of society and technology

Compared to the foundation of information theory, depiction of complexity has been developed for a longer time, but it is still far less perfect. The essential reason is that there is no absolute scale for complexity without any definition for its basic framework. According to the statistics of Lloyd, definition of complexity is far beyond the actual situation. For example, according to Ghelman, scholar from America, complexity is the conceptual expression of orderliness, structural hierarchy and morphological diversity during system evolution, which is called effective complexity. According to British encyclopedia article, the features of complexity include connectivity, non-centralized controlling, instability, emergence, polarization, diversification and evolution capability. According to French scholar, Edgar Morland, complexity is either ordered or disordered, either random or organizational. He proposed that the essence of the world is jointly constituted by orderliness and disorderliness. According to Santa Fe institute, complex system is a network system which constitutes of large amounts of different and interactive units. Research on complexity is to study how complex system produces organizational behaviors under certain rules. According to Professor Qian Xuesen, the essence of complexity is the dynamic characteristic of Open Complex Giant System.

Generally, definition of complexity can be concluded into three kinds comprehensively.

Systematic complexity is also called ontological complexity, including complexity of systematic state, systematic structure and function. Structural complexity means the amount of random units with mutual effect on each other. The interrelation percentage changes with interactive strength of individual unit; while functional complexity changes with the complete behaviors of recovery system.

The complexity of problem is described by the solution of problem complexity.

Problem solving complexity is related to computer complexity. They can be concluded as the complexity of epistemology.

Estimation of information system functions is an important section of information system engineering. During the production of engineering software, an adjustable, experienced, quantitative and delicate measurement for software scale is the basis for formulating software plans. The non-quantitative estimation based on experience totally is usually unreliable, which should be avoided as much as possible. At present, there are many methods of software estimation, such as code line technology, task estimation technology, model, model of functional points, model of object points, predictive estimation by experts, budget model of neural network and so on. In comparison, the functional point model is the most effective model since it measures a system from the perspective of users, which has nothing to do with degree design language. Therefore, it can be used for structural modeling scheme as well as modeling scheme for objects. At the early stage of systematic development, demand analysis model can be employed to estimate functional points. 
Besides, these two models have their professional organization for administrative research. The information system can be constantly perfected by issuing new versions during its development.

The importance of functional measurement for the scale has been constantly promoted since the application of engineering methods and principles to information system development. Fig. 1 below shows a general process of software scale measurement. As the figure shows, measurement of software scale has two basic stages, which are mapping stage and evaluation stage. The mapping stage is to represent software with application of concept and definition; while evaluation stage is to calculate elements for measurement according to particular rules and processes.

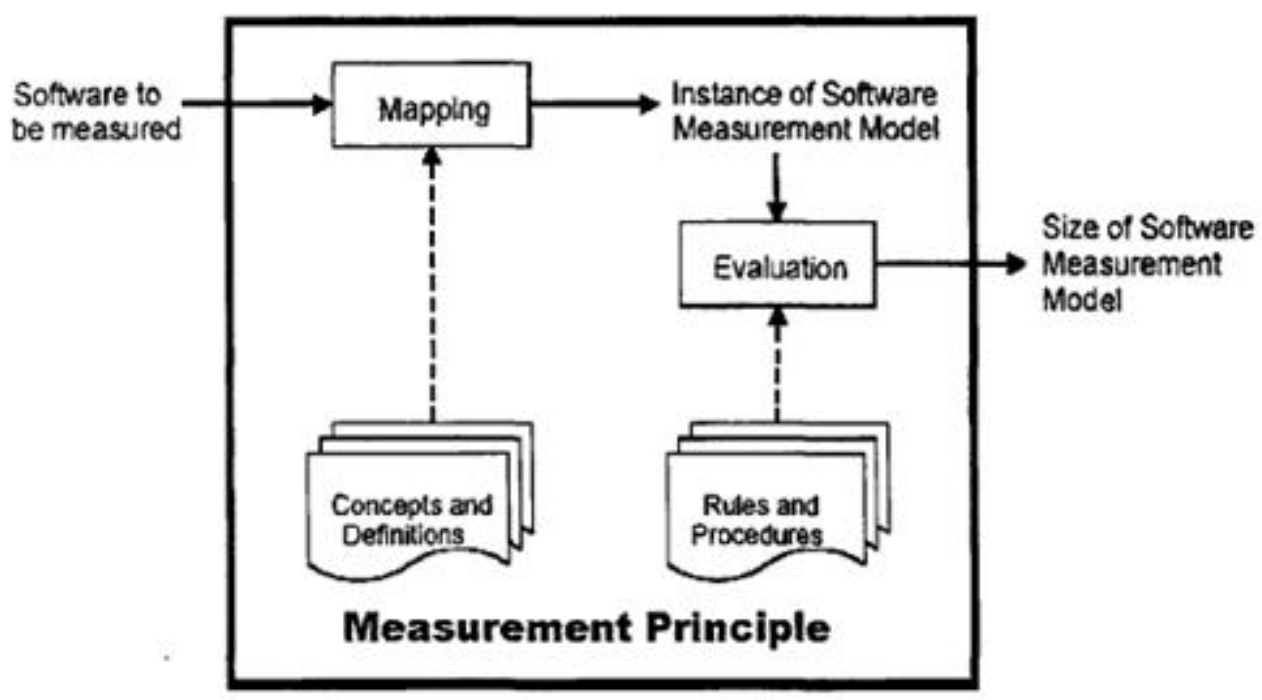

Fig. 1 General process of measuring software scale

The intellectualized information system for comprehensive management is an important part of Coke Wharf of of Tianjin Port Stock Company during the company's informatization construction. Meanwhile, it is also important means and technological support to be adapted to future development trend, promoting port's administrative level, implementing administrative revolution and solidifying advanced administrative mind.

China has become a member of organization, so it is necessary to confront with complicated and changeable world economic environment. Information is important strategic resource for developing modern harbor enterprises and it is also important service content of harbor enterprises.

Coke Branch Company of Tianjin Port Stock Company, which is short for Coke Company has decided to adopt the advanced computer processing technology and network communication technology based on the advanced and high-end administrative mind. The company aims to build their intellectual information system for comprehensive management based on process optimization.

\section{Conclusions}

In the paper, it mainly studies the formation and development of information system, summaries the development trend of information system as well as its research, proposes systematic structural model of information system development, analyzes the reasons for the complex information system during development, introduces the analysis model of functional points, designs analysis algorithm with functional points for demand model, and estimates functional complexity degree and development cost for information system developers. At last, by taking intellectua lized information 
system for comprehensive management in Tianjin Port Coke Wharf Branch as an example, the paper estimates the functional complexity and development cost with the application of analysis model of this functional point with a comparison with the actual development cost at last. Practice proves that it can help system developers to estimate project work, time and cost while modeling the project with the help of functional analysis algorithm since it can be operated easily with reliable estimat ion result in practical engineering application. The project complexity degree and development cost can be determined in the early stage by estimating project scale with this method, which can provides powerful technological support for planning and arranging project development and progress.

\section{References}

[1] Nunamaker Jr J F, Chen M. Systems development in information systems research[C]//System Sciences, 1990., Proceedings of the Twenty-Third Annual Hawaii International Conference on. IEEE, 1990, 3: 631-640.

[2] Benbasat I, Goldstein D K, Mead M. The case research strategy in studies of information systems[J]. MIS quarterly, 1987: 369-386.

[3] Xia W, Lee G. Complexity of information systems development projects: conceptualization and measurement development[J]. Journal of Management Information Systems, 2003, 22(1): 45-83.

[4] Byström K, Järvelin K. Task complexity affects information seeking and use[J]. Information processing \& management, 1995, 31(2): 191-213.

[5] Orlikowski W J, Baroudi J J. Studying information technology in organizations: Research approaches and assumptions[J]. Information systems research, 1991, 2(1): 1-28.

[6] Lewis M H. Environmental complexity and central nervous system development and function[J]. Mental retardation and developmental disabilities research reviews, 2004, 10(2): 91-95.

[7] Wand Y, Weber R. Research commentary: information systems and conceptual modeling - a research agenda[J]. Information Systems Research, 2002, 13(4): 363-376.

[8] Wood R E. Task complexity: Definition of the construct[J]. Organizational behavior and human decision processes, 1986, 37(1): 60-82.

[9] March S T, Smith G F. Design and natural science research on information technology[J]. Decision support systems, 1995, 15(4): 251-266.

[10]Da Silveira G, Borenstein D, Fogliatto F S. Mass customization: Literature review and research directions[J]. International journal of production economics, 2001, 72(1): 1-13. 